Review

\title{
A comprehensive review on the colorless carotenoids phytoene and phytofluene
}

\author{
Antonio J. Meléndez-Martínez*, Paula Mapelli-Brahm, Ana Benítez-González, Carla M. Stinco \\ Food Colour \& Quality Laboratory, Department of Nutrition \& Food Science, Universidad de Sevilla, 41012 Seville, Spain
}

\begin{abstract}
A B S T R A C T
Carotenoids and their derivatives are versatile isoprenoids involved in many varied actions, hence their importance in the agri-food industry, nutrition, health and other fields. All carotenoids are derived from the colorless carotenes phytoene and phytofluene, which are oddities among carotenoids due to their distinct chemical structure. They occur together with lycopene in tomato and other lycopene-containing foods. Furthermore, they are also present in frequently consumed products like oranges and carrots, among others. The intake of phytoene plus phytofluene has been shown to be higher than that of lycopene and other carotenoids in Luxembourg. This is likely to be common in other countries. However, they are not included in food carotenoid databases, hence they have not been linked to health benefits in epidemiological studies. Interestingly, there are evidences in vitro, animal models and humans indicating that they may provide health benefits. In this sense, the study of these colorless carotenes in the context of food science, nutrition and health should be further encouraged. In this work, we review much of the existing knowledge concerning their chemical characteristics, physico-chemical properties, analysis, distribution in foods, bioavailability and likely biological activities.
\end{abstract}

\section{Keywords:}

Colorless carotenoids

Phytoene

Health

Food

Nutrition

\section{Introduction}

Phytoene $\left(7,8,11,12,7^{\prime}, 8^{\prime}, 11^{\prime}, 12^{\prime}\right.$-octahydro- $\psi, \psi$-carotene, $\left.\mathrm{PT}^{1}\right)$ and phytofluene $\left(7,8,11,12,7^{\prime}, 8^{\prime}\right.$-hexahydro- $\psi$, $\psi$-carotene, PTF) were already studied in the 1940s, with a wealth of dedicated investigations in the 1950s [1-7]. They can be considered as rarities within the "Carotenoid Kingdom" as they are colorless. However, they are key carotenoids because they are precursors of all the

\footnotetext{
* Corresponding author at: Food Colour \& Quality Laboratory, Department of Nutrition \& Food Science, Universidad de Sevilla, Facultad de Farmacia, 41012 Sevilla, Spain.

E-mail address: ajmelendez@us.es (A.J. Meléndez-Martínez).

1 Abbreviations used: ABA, abscisic acid; ABTS, [2,2'-azinobis-(3-ethylbenzothiazoline-6-sulfonic acid)]; ACC-1, acetyl-CoA carboxylase; CD, control diet; CD36, cluster of differentiation 36; CPT-1, carnitine palmitoyltransferase ; CRTISO, carotenoid isomerase; DGAT, diacylglycerol acyltransferase; DMAPP, dimethylallyl diphosphate; DXP, 1-deoxy-D-xylulose-5-phosphate; E, energy; FFA, free fatty acid; FPP, farnesyl pyrophospate; GGPP, geranylgeranyl pyrophosphate; GPP, geranyl pyrophospate; HDL, high density lipoprotein; HFD, high-fat diet; IPP, isopentenyl diphosphate; LDL, low density lipoprotein; LYC, lycopene; $\mathrm{MeOH}$, methanol; MEP, methylerythritol 4phosphate; MTBE, methyl-tert-butyl ether; MVA, mevalonic acid; PDS, phytoene desaturase; PPAR, peroxisome proliferator-activated receptors; PPAR $\gamma$, peroxisome proliferator-activated receptor gamma; PT, phytoene; PTF, phytofluene; SREBP-1, sterol-regulatory element binding protein; TEAC, trolox equivalent antioxidant capacity; VLDL, very low density lipoprotein; ZDS, $\zeta$-carotene desaturase; ZISO, $\zeta$ carotene isomerase; c.d.b., conjugated double bonds.
}

others. This is why they have been extensively studied in investigations dealing with the biosynthesis of these compounds. Surprisingly, they have been largely neglected as compared to other carotenoids in other kinds of studies, despite they are known to occur in widely consumed foods. Likewise they are among the predominant carotenoids in human plasma and tissues. In this work, aspects like chemical features, properties, analysis, occurrence in foods, bioavailability and likely biological activities of PT and PTF are reviewed.

\section{Chemical structure and physico-chemical properties}

PT and PTF are linear hydrocarbons with molecular formulae $\mathrm{C}_{40} \mathrm{H}_{64}(\mathrm{MW}=544 \mathrm{Da})$ and $\mathrm{C}_{40} \mathrm{H}_{62}(\mathrm{MW}=542 \mathrm{Da})$, respectively. More specifically, they are alkenes with 9 and 10 double bonds, respectively. In the case of PT, three of the double bonds are conjugated, whereas PTF has five conjugated double bonds (c.d.b.) (Fig. 1) [8]. The system of alternating double and single bonds is one of the main structural characteristics of carotenoids. This is an electron-rich conjugated system in which the $\pi$-electrons are delocalized and is considered the structural feature mainly related to the light-absorbing properties, reactivity and shape of carotenoids [9]. The system of c.d.b. in PT and PTF is clearly shorter compared to other dietary carotenoids (for instance, lycopene, another 


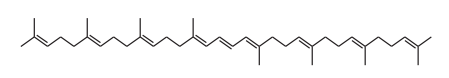

(All- E)-phytoene

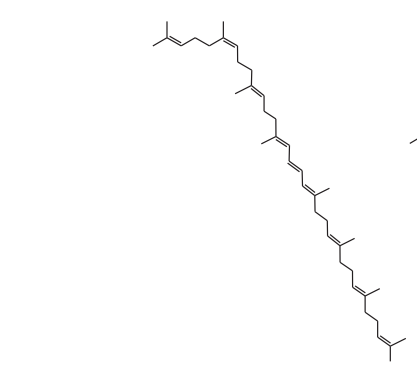

(5Z)-phytoene

(13Z)-phytoene

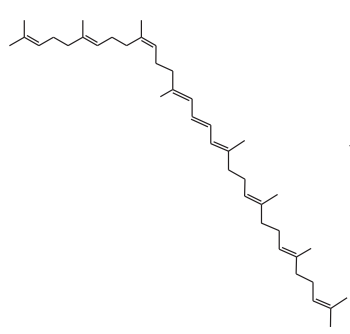

(9Z)-phytoene

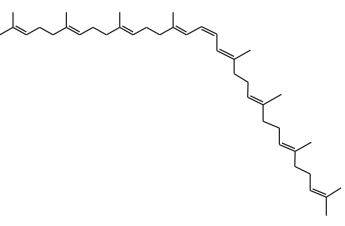

(15Z)-phytoene

Representation of some phytoene geometrical isomers

Fig. 1. Chemical structures of possible geometrical isomers of phytoene and phytofluene.

linear carotene, contains 11 c.d.b.) (Fig. 2), so both PT and PTF are expected to exhibit important differences in some physicochemical properties compared to other carotenoids.

\section{Light absorbing properties}

According to the data tabulated in reference books, PT absorbs maximally at $286 \mathrm{~nm}$ and the spectrum also exhibit two shoulders at 276 and $297 \mathrm{~nm}$ in petroleum ether, its fine structure being low (\%III/II $=10)$. In the case of PTF, the $\lambda_{\max }$ is 348 in petroleum ether. The spectrum has sharp absorption bands $(\% \mathrm{III} / \mathrm{II}=90)$ with other absorption maxima at 331 and $367 \mathrm{~nm}[10,11]$. The relationships between the length and arrangement of the system of c.d.b. of common dietary carotenoids on the color parameters of the CIELAB uniform space is well understood. Although the color of carotenoids is dependent on factors others than just their chemical structure (like concentration and interaction with other molecules, among others), it is considered that at least 7 c.d.b. are needed for a carotenoid to exhibit color [12], hence PT and PTF are considered colorless carotenoids. On the other hand PTF is known to fluorescence at around $510 \mathrm{~nm}$ when it is excited with near-UV light [13]. This property can be certainly used to enhance its detection or for other analytical purposes.

\section{Reactivity}

In contrast to other carotenoids, there are not many specific data relative to the susceptibility of PT and PTF to oxidation in model systems. In a recent study, this was compared in PT, PTF and LYC by in silico strategies and the ABTS radical cation decoloration assay. The theoretical and experimental results were found to agree well and indicated that, as it could be presumed from their chemical structures, PT and PTF were not as effective antiradicals

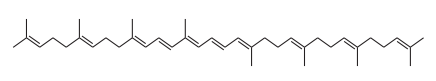

(All-E)-phytofluene

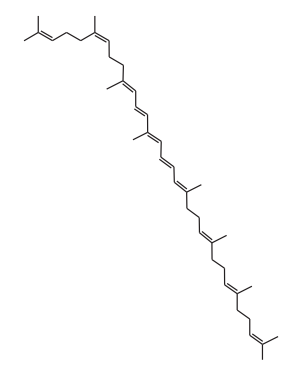

(5Z)-phytofluene

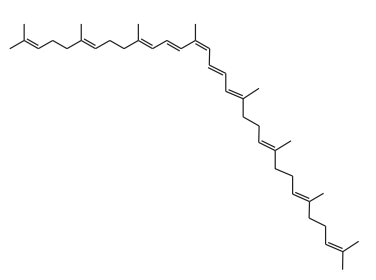

(13Z)-phytofluene

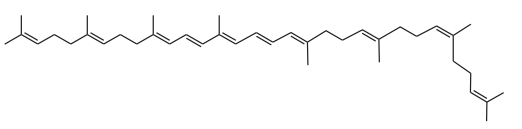

(5'Z)-phytofluene

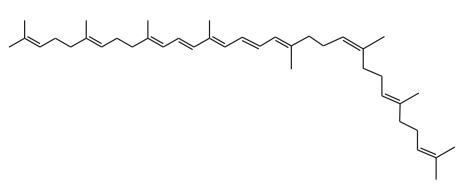

(9'Z)-phytofluene

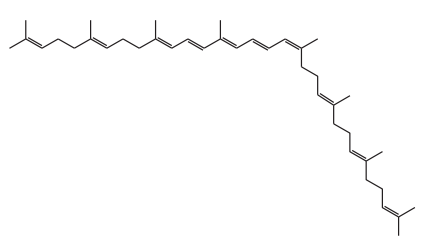

(13'Z) -phytofluene

Representation of some phytofluene geometrical isomers

Fig. 1 (continued)

as LYC. However, the comparison of the experimental TEAC with those reported for other carotenoids by other authors indicated that PT and PTF seem to be better scavengers of the ABTS radical cation than it may be expected beforehand [14]. Interestingly, and contrary to what it could be expected from its structure, PTF is known to be very unstable in the presence of oxygen [8]. More studies assessing the behavior of these carotenoids under different oxidation conditions and by other approaches are warranted.

\section{Shape}

The study of the geometry of molecules as well as their size or presence of functional groups is important to help understand where they can fit in structures or how they interact with other 
molecules [9]. PT and PTF are, like LYC, linear carotenes that do not contain rings in their structures [8]. The polyene chain of c.d.b. confers rigidity to the carotenoid molecule. Since the number of c.d.b. is much lower in PT and PTF than in LYC, they are expected to adopt shapes very different relative to most carotenoids in general and LYC in particular.

On the other hand, the differentiation between different geometrical isomers of carotenoids (Fig. 1) is important as they can exhibit important differences in shape and some properties. This differences can in turn have an impact in their solubilization, stability, absorption, metabolism and transport [9,15-17], and therefore in their possible biological actions.

As far as PT and PTF are concerned, it is well-known that (15Z)phytoene is the predominant PT isomer in most carotenogenic organisms [18,19]. (15Z)-Phytofluene is also thought to be the predominant isomer in many sources $[8,19]$. Several geometrical isomers of PTF are known to occur in red tomatoes, although their conclusive identification remains obscure $[20,21]$. At least 3 geometrical isomers of PT and 6 of PTF can be readily formed and detected by using conventional stereomutation procedures and routine analytical procedures [22]. Chemical and in silico evidences indicate that certain $Z$-isomers of both phytoene and phytofluene could be thermodynamically favoured over the respective (all-E)isomers [23].

\section{Biosynthesis}

Carotenoids are biosynthesized by all photosynthetic organisms as well as some non-photosynthetic bacteria and fungi. In any case, the typical commited step of carotenoid biosynthesis is the condensation of two molecules of the C20 compound geranylgeranyl pyrophosphate (GGPP) to form (15Z)-phytoene, the major PT isomer in most carotenogenic organisms [18,19], as stated before. This reaction is catalyzed by the enzyme phytoene synthase (PS), which is a key regulatory enzyme in the pathway [24-27]. Phytoene is therefore the precursor of all carotenoids. Phytofluene is formed by the action of phytoene desaturases, which insert one double bond extending the system of conjugated double bonds by two (Fig. 2). (15Z)-Phytofluene is also thought to be the predominant isomer in many sources $[8,28]$. The evolution of the carotene desaturation reactions has been comprehensively reviewed by Sandmann [29].

\section{Fungi and some bacteria}

The formation of phytoene from GGPP is catalyzed by a phytoene synthase generally referred to as CRTB. The biosynthesis of lycopene from phytoene is thought to be catalyzed by only one desaturase enzyme, encoded by crtI (reviewed in [30,31]) (Fig. 2). CRTI is found in fungi and some prokaryotes like heliobacteria, green filamentous bacteria, purple photosynthetic bacteria and other bacteria that biosynthesize carotenoids (with the exception of green-sulfur bacteria and cyanobacteria) [32]. Rhodobacter capsulatus was the bacteria species from where the crtI gene was first cloned $[33,34]$. Some years later, such gene was cloned from the fungus Neurospora crassa [35]. There is evidence that the cyanobacteria Gloeobacter violaceus carries out the synthesis of lycopene like non-photosynthetic bacteria (i.e. by means of CRTI). This is an exception among oxygenic photosynthetic organisms. In this regard, it is thought that, in ancestral cyanobacteria, the desaturation of phytoene was initially catalyzed by CRTI, although this protein was eventually replaced by CRTP and other desaturases, which would be acquired later $[32,36,37]$. A strategy to produce 13C-labeled phytoene in Escherichia coli by using 13C-glucose as carbon source has been recently described. In brief, carotenogenic genes from Enterobacter agglomerans were inserted in E. coli, and the function of the CRTI protein was modified by error-prone PCR to obtain strains accumulating that carotenoid. The 13C-labeled phytoene is expected to expand our knowledge about the fate of this carotenoid in animals [38].

\section{Oxygenic photosynthetic organisms}

Currently it is generally accepted that the desaturation of phytoene $\left(7,8,11,12,7^{\prime}, 8^{\prime}, 11^{\prime}, 12^{\prime}\right.$-octahydro- $\psi, \psi$-carotene $)$ to form successively phytofluene $\left(7,8,11,12,7^{\prime}, 8^{\prime}\right.$-hexahydro- $\psi, \psi$-carotene $)$,

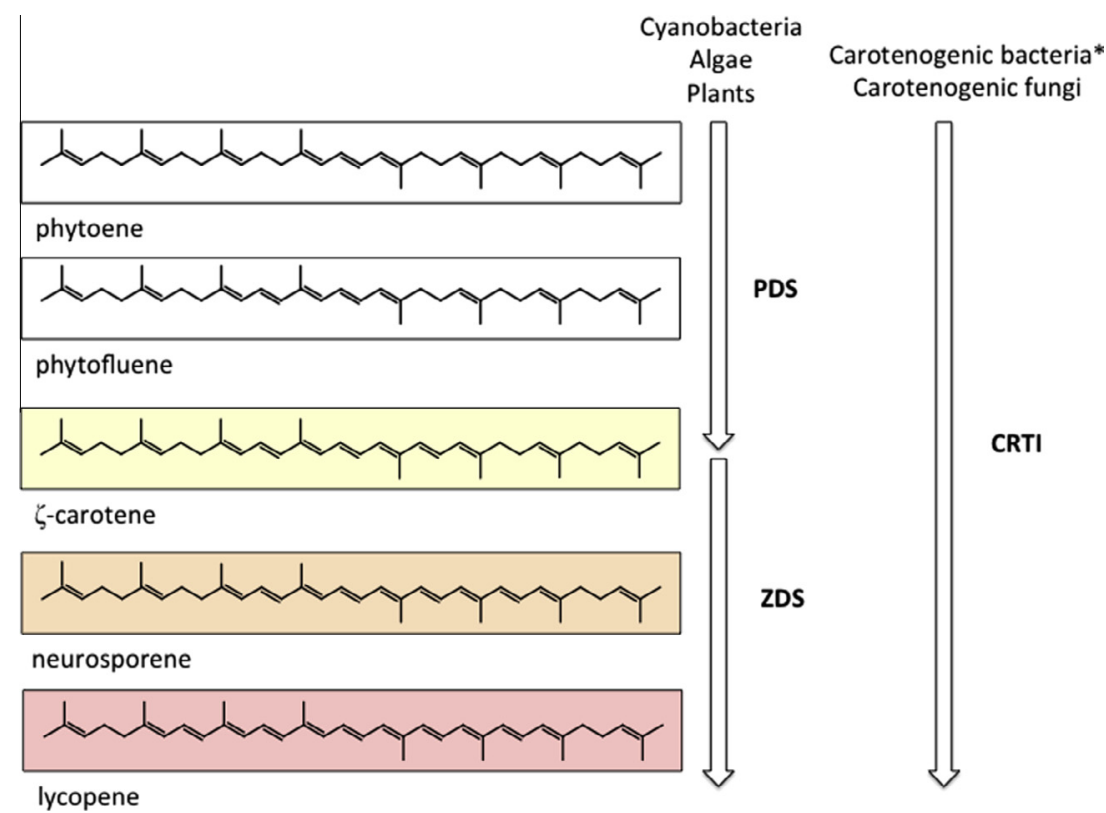

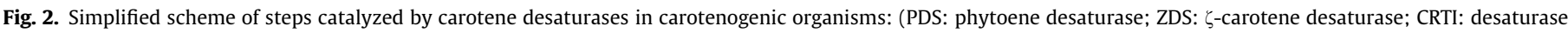
encoded by the crtI gene). *Exept cyanobacteria. 
$\zeta$-carotene $\left(7,8,7^{\prime}, 8^{\prime}\right.$-tetrahydro- $\psi, \psi$-carotene $)$, neurosporene $(7,8$ dihydro- $\psi, \psi$-carotene) and finally lycopene $(\psi, \psi$-carotene) in plants requires four steps. These are catalyzed by enzymes like phytoene desaturase (PDS), $\zeta$-carotene isomerase (ZISO), $\zeta$-carotene desaturase (ZDS) and carotenoid isomerase (CRTISO) (Fig. 2). Light-mediated photoisomerization is also required at some steps [27,39-43]. The bleaching compounds used to inhibit desaturases in these organisms were found to not be effective in bacteria and fungi. This observation added support to the hypothesis that the carotene desaturation was markedly distinct between both groups of organisms [29].

\section{Cyanobacteria}

The enzymes involved in the synthesis of phytoene and phytofluene in several cyanobacteria (like Synecocystis sp., Gloeobacter sp. or Synechococcus sp., Chlorobaculum sp.) have been the subject of several studies [36,44-47]. The desaturation of phytoene to eventually form lycopene is accepted to need in most cases three proteins, namely CrtP (a phytoene desaturase that catalyzes the formation of $\zeta$-carotene via phytofluene), $\mathrm{CrtQ}$ ( $\zeta$-carotene desaturase) and $\mathrm{CrtH}$ (cis-carotene isomerase) [32]. The first phytoene desaturase gene (specifically $\mathrm{crtP}$ ) from an organism with oxygenic photosynthesis was obtained from Synechococcus PCC7942 [48].

\section{Algae}

An interesting topic in the biosynthesis of carotenoids in algae is the number of Psy gene types found in some species. There are diatoms (Phaeodactylum tricornutum, Thalassiosira pseudonana), red (Cyanidioschyzon merolae) and green algae (Volvox carteri, Chlamydomonas reinhardtii, Chlorella vulgaris) with only one class of such gene [49,50]. Contrastingly, some other contain two classes of Psy genes, like green algae from Ostreococcus sp. and Micromonas sp. These and others contain two copies, which leads to hypothesize that there existed an old gene duplication event that resulted in the occurrence of two classes of PSY in some algae. Studies in other green algae like members of the Dunaliella sp. seem to indicate that there may have also been more recent gene duplication episodes. The presence of at least two classes of PSY enzymes in algae may indicate that these can be regulated distinctly depending on factors like developmental stages or environmental stresses for the adequate biosynthesis of carotenoids [31,50]. This is certainly important for the biotechnological production of carotenoids for commercial purposes.

\section{Plants}

Genes encoding phytoene synthase have been identified in several plants, like Arabidopsis, melon, Citrus sp., daffodil, marigold, pepper, poplar, wheat, maize, rice, tomato and others. In rice, poplar, tomato, wheat and maize there are two or more homolog genes, whereas only one has been identified in Arabidopsis [5163]. The presence of two or more PSY enzymes seems to be important in the control of carotenoid biosynthesis in different organs, at different developmental stages or in response to environmental stimuli, including stresses like salt and drought [27]. As an example, two phytoene synthase genes (Psy1 and Psy2) are known to exist in tomatoes, the expression of the former is increased in the fruit during its ripening, whereas Psy1 expression predominates before [64,65]. On the other hand, maize PSY proteins can be encoded by three paralogous genes. PSY1 is expressed in leaves and the seed endosperm and confer to the latter its characteristic yellow color. PSY2 is also expressed in leaves, whereas PSY3 is expressed in roots. The expression of the latter has been shown to be induced by stress $[51,55,66,67]$. The localization of PSY1 isozymes is attracting much attention [68,69]. Interestingly, there is evidence that allelic variation may affect the enzymatic activity of PSY. As an example it has been shown in wheat that alternative splicing resulted in the formation of four different transcripts, of which only one proved to be functional [54].

Being a key regulatory enzyme in carotenoid biosynthesis, PSY has been important for the modification of the carotenoid levels in crops by genetic engineering [70-74]. Psy from daffodil (along with the bacterial phytoene desaturase $(r t I$ ) was introduced into rice for the development of Golden Rice [75]. By replacing the daffodil phytoene synthase gene with the maize Psy1 gene, Golden Rice 2 (accumulating higher amounts of $\beta$-carotene) was obtained [76]. At the transcriptional level, plant Psy genes have been shown to respond to abscisic acid (ABA), temperature, photoperiod, developmental events, high light, stresses (salt, drought) and post-transcriptional feedback [27].

Phytoene desaturase (PDS) is the enzyme that introduces further double bonds in phytoene to form $\zeta$-carotene via phytofluene. Genes encoding this protein have been identified and obtained from plants like Arabidopsis, tomato, pepper, maize, daffodil, soybean, tobacco and some others [56,61,77-81].

PDS has been long known to be an important target site for bleaching herbicides like norflurazon and fluridone, among others. Phytoene is accumulated at the expense of the typical colored carotenoid as a result. This subject has been studied in detail cyanobacteria, algae and plants [82-87]. In a novel approach, norflurazon has been used in tomato cell cultures containing 14C-sucrose in the medium to produce 14C-labeled phytoene to gain further insight into the bioavailability and biological actions of this carotenoid [88].

\section{Analysis}

\section{Separation}

\section{Thin-layer chromatography and open-column chromatography}

Examples of separations and chromatographic parameters for the analysis of phytoene and phytofluene by classical chromatographic techniques can be found in classical reference books for carotenoid analysis. Due to their lack of color their bands cannot be detected with the naked eye. Fluorescence can be used to "reveal" the presence of phytofluene [11].

\section{Liquid chromatography}

The normal phase HPLC separation of isomers of both phytoene and phytofluene on an aluminum oxide column has been reported [89]. Likewise the HPLC separation of up to 6 isomers of phytofluene on a calcium hydroxide column has been described [20].

In reverse phase $C_{18}$ columns, this elution order is typically observed: phytofluene elutes before phytoene and both after other food carotenes like lycopene, $\zeta$-carotene, $\alpha$-carotene and $\beta$-carotene $[11,90]$. A rapid method allowing the isocratic separation of phytoene and phytofluene, along with other carotenoids, retinoids and tocopherol in $12 \mathrm{~min}$, using a Spheri-5-ODS column is well described [91]. An ultra-high-pressure liquid chromatography (UHPLC) method for their analysis along with 14 other carotenoids have been recently proposed [92]. Likewise, a microextraction method and a rapid liquid chromatography method have been developed for the simultaneous determination of phytoene and phytofluene along with other dietary carotenoids, tocopherols and chlorophylls [93]. These rapid methodologies are recommendable for screening purposes, as the separation of some carotenoid isomers is not as effective as with other methodologies, mainly using $\mathrm{C}_{30}$ columns.

In reverse phase $C_{30}$ columns, this elution order is typically observed: the major phytoene geometrical isomers elute before the major phytofluene isomers. The main $\beta$-carotene and lycopene isomers elute later [22,94-96]. 
It is interesting to note that coelutions of phytofluene with other non-carotenoid lipid compounds in animal samples (like cholesteryl esters) have been reported [90].

\section{Detection}

\section{UV-Vis spectroscopy}

Typical spectra in a $\mathrm{MeOH} / \mathrm{MTBE}$-based mobile phase are shown in Fig 3. Spectroscopic data of different geometrical isomers of phytoene and phytofluene have been reported elsewhere [22].

\section{Fluorescence}

As stated earlier phytofluene is known to fluoresce at around $510 \mathrm{~nm}$ when excited with near-UV light [13]. As an example, excitation and emission wavelengths of 346 and $520 \mathrm{~nm}$, respectively, have been used [97]. By using this kind of detection a markedly better sensitivity can be obtained. As an example, the fluorimetric detection of phytofluene from serum samples as small as $200 \mu \mathrm{l}$ has been described. The objective of this study was to assess its possible interference in the fluorimetric detection of serum vita$\min \mathrm{A}[98]$.

\section{Mass spectrometry}

Information about characteristics fragments obtained by electron impact ionization (EI) can be found in the Handbook of Carotenoids [8] and elsewhere [99]. In the case of phytoene diagnostic fragments at $m / z 544$ (molecular ion), 450, 339 and 69, among others, are reported. In the case of phytofluene diagnostic fragments at $\mathrm{m} / \mathrm{z} 542$ (molecular ion), 448, 405, 337 and 69, among others, are reported.

MS data obtained by HPLC-MS/MS using atmospheric pressure chemical ionization (APCI) in positive mode are also well described in the literature. Fragments at $m / z 545,489,435,395$ and 339 were detected as characteristic for phytoene, and at $m / z 543,461,406$ and 338 for phytofluene [96,100].

Matrix-assisted laser desorption ionization coupled to time-offlight mass spectrometry (MALDI/TOF-MS) has also been used for the identification of phytoene, phytofluene and other plant carotenoids. Very high mass accuracy as well as very high sensitivity (picomolar) can be obtained by this approach. Masses accuracies of 84 and $26 \mathrm{ppm}$ were reported in their analysis in a tomato mutant, specifically Tangella [101].

\section{Nuclear magnetic resonance}

${ }^{1} \mathrm{H}$ and ${ }^{13} \mathrm{C}$ NMR assignments of phytoene and phytofluene are reported in classical works $[102,103]$. A methodology for the rapid NMR identification of tomato carotenoids, including (15Z)- phytoene, involving a $\mathrm{CDCl} 3$ extraction procedure and high-resolution multidimensional NMR techniques using a cryogenic probe is described [104]. The identification of both carotenoids in tomato juice by ${ }^{1} \mathrm{H}$-NMR coupled to HPLC has also been reported [105].

\section{Occurrence in foods, dietary intake and possible epidemiological implications}

\section{Occurrence in foods}

The content of secondary metabolites like carotenoids in foods are dependent on factors of different nature like genetic, agronomic or technological ones [106]. Very important content differences (ca. 4-fold in the case of phytofluene and ca. 6-fold in the case of phytoene) even in tomatoes of the same variety cultivated under the same conditions have been observed [21]. The meaningful comparison of phytoene and phytofluene levels between different foods is therefore very complicated. In order to classify their content in common foods we have compiled data reported in the literature and determine, whenever possible, their average content and range in different samples. The criteria proposed by Britton and Khachik [107] to categorize the carotenoid levels in food sources as low (those containing between 0 and $0.1 \mathrm{mg} / 100 \mathrm{~g}$ of fresh weight), moderate (between 0.1 and $0.5 \mathrm{mg} / 100 \mathrm{~g}$ of fresh weight), high (0.5-2 mg/100 g of fresh weight) or very high (more than $2 \mathrm{mg} / 100 \mathrm{~g}$ of fresh weight), was followed. The results are summarized in Table 1. As it can be observed, large quantitative differences within the same food are common. In virtually all the cases, the phytoene content was higher relative to phytofluene. High or very high contents of them can be found for instance in apricot, carrots, tomatoes and derivatives, red grapefruits, watermelon and some peppers (Table 1 ).

Apart from these foods, the presence of colorless carotenoids has been described in palm oil [108,109], gac [110], yellow passion fruit [99], loquats [95], citrus mutants [111-114], buriti, mamey, marimari, and physalis [94], among others.

\section{Dietary intake}

The dietary intake of phytoene and phytofluene has been largely ignored, very probably because of their absence in the classical carotenoid databases. To the best of our understanding, the only existing study that consider it is the one by Biehler et al. [115]. The Luxembourgish daily intakes per person were estimated to be $2.0 \mathrm{mg}$ in the case of phytoene and $0.7 \mathrm{mg}$ in the case of phytofluene. Interestingly the estimated daily intake of lycopene was lower $(1.8 \mathrm{mg})$ than that of phytoene. The percentage intake of

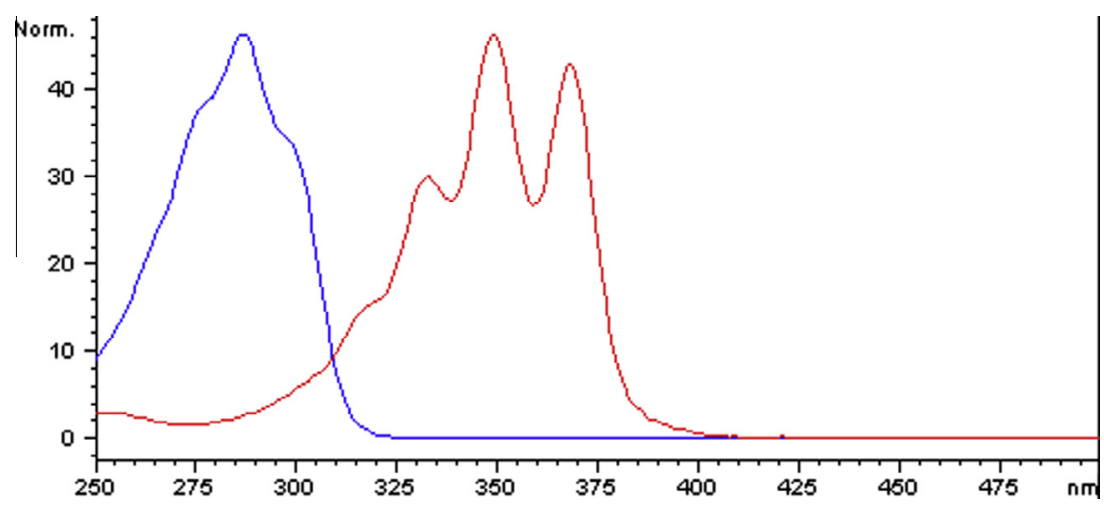

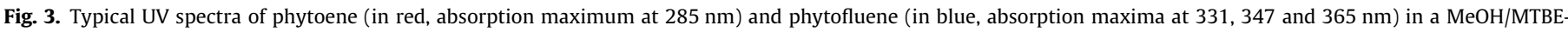
based mobile phase. 
Table 1

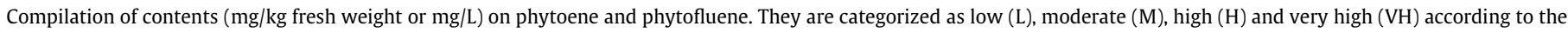
criteria proposed by Britton and Khachik [107].

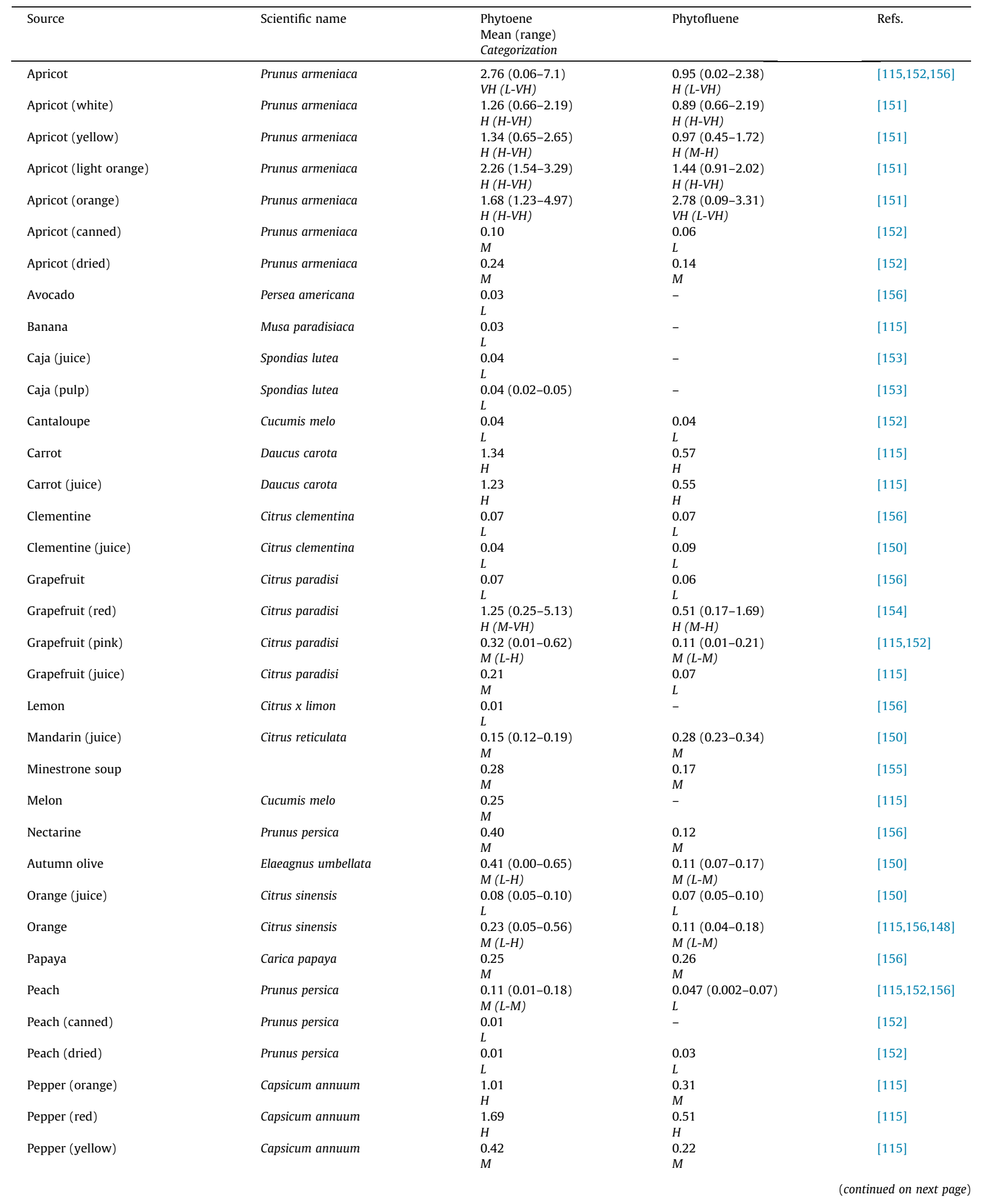


Table 1 (continued)

\begin{tabular}{|c|c|c|c|c|}
\hline Source & Scientific name & $\begin{array}{l}\text { Phytoene } \\
\text { Mean (range) } \\
\text { Categorization }\end{array}$ & Phytofluene & Refs. \\
\hline Spaguetti sauce & & $\begin{array}{l}2.77 \\
V H\end{array}$ & $\begin{array}{l}0.16 \\
M\end{array}$ & {$[155]$} \\
\hline Tomato & Solanum lycopersicum & $\begin{array}{l}1.0(0.6-1.38) \\
H\end{array}$ & $\begin{array}{l}0.45(0.40-0.51) \\
M(M-H)\end{array}$ & {$[115,156,152]$} \\
\hline Tomato (whole canned) & Solanum lycopersicum & $\begin{array}{l}1.86 \\
H\end{array}$ & $\begin{array}{l}0.82 \\
H\end{array}$ & {$[155]$} \\
\hline Tomato (paste) & Solanum lycopersicum & $\begin{array}{l}4.94(1.52-8.36) \\
V H\end{array}$ & $\begin{array}{l}2.85(2.08-3.63) \\
V H\end{array}$ & {$[155,152]$} \\
\hline Tomato (juice) & Solanum lycopersicum & $\begin{array}{l}1.77(1.64-1.90) \\
H\end{array}$ & $\begin{array}{l}0.63(0.44-0.83) \\
H(M-H)\end{array}$ & {$[115,155]$} \\
\hline Tomato (ketchup) & & $\begin{array}{l}3.44(3.39-3.49) \\
V H\end{array}$ & $\begin{array}{l}1.29(1.03-1.54) \\
H\end{array}$ & {$[115,155]$} \\
\hline Tomato (soup) & Solanum lycopersicum & $\begin{array}{l}1.72 \\
H\end{array}$ & $\begin{array}{l}0.72 \pm 0.18 \\
H\end{array}$ & {$[155]$} \\
\hline Tomato (sauce) & Solanum lycopersicum & $\begin{array}{l}2.95 \\
V H\end{array}$ & $\begin{array}{l}1.27 \\
H\end{array}$ & {$[155]$} \\
\hline Tomato (puree) & Solanum lycopersicum & $\begin{array}{l}2.40 \\
V H\end{array}$ & $\begin{array}{l}1.08 \\
H\end{array}$ & {$[155]$} \\
\hline Vegetable beef soup & & $\begin{array}{l}0.35 \\
M\end{array}$ & $\begin{array}{l}0.19 \\
M\end{array}$ & {$[155]$} \\
\hline Vegetarian soup & & $\begin{array}{l}0.60 \\
H\end{array}$ & $\begin{array}{l}0.31 \\
M\end{array}$ & [155] \\
\hline Vegetable juice & & $\begin{array}{l}1.71 \\
H\end{array}$ & $\begin{array}{l}0.69 \\
H\end{array}$ & [155] \\
\hline Watermelon & Citrullus lanatus & $\begin{array}{l}1.17 \\
H\end{array}$ & $\begin{array}{l}0.44 \\
M\end{array}$ & {$[115]$} \\
\hline
\end{tabular}

phytoene + phytofluene was $16 \%(2.7 \mathrm{mg})$ of total carotenoid intake [115].

\section{Possible epidemiological implications}

Phytoene and phytofluene are found together with lycopene in tomato products and other lycopene-containing foods like watermelons, red grapefruits, etc., although their individual concentrations are typically lower. However, their distribution is much broader and they occur in products very frequently consumed like oranges and carrots, among others, as it can be observed in Table 1 and the study by Biehler et al. [115]. In this sense it would not be surprising to find higher dietary intakes of phytoene or phytoene + phytofluene relative to lycopene in other countries. This is of great importance from an epidemiological point of view and raises the question of whether the colorless carotenoids were "undercover" in the studies finding associations between the consumption of tomatoes and health benefits. The effects of tomato product supplementation on biomarkers of oxidative stress and carcinogenesis in human clinical trials was reviewed by Basu and Imrhan [116]. One of the main conclusions of their study was that the consumption of tomato products leads to health benefits, although those should be related to the occurrence of lycopene together with several compounds naturally present in tomatoes. According to this review, there is limited in vivo evidence on the health benefits of lycopene on its own as the majority of the clinical trials evaluated suggest the existence of synergistic effects involving lycopene and other compounds in reducing the levels of the biomarkers evaluated [116]. On the other hand, a recently published study concludes that there is evidence for an inverse association between lycopene intake and risk of cardiovascular disease, albeit more research is required to demonstrate if lycopene or other tomato compounds are responsible for such association [117]. In this sense it is important to note that, aside from carotenoids, tomatoes also contain other nutritionally relevant compounds like phenolic compounds and ascorbic acid, among others, and that synergistic effects among different species can occur $[118,119]$.

\section{Bioavailability}

Laboratory animals

Rats

Phytoene and phytofluene were found to be bioavailable in Sprague-Dawley rats fed a dry powder $(1 \mathrm{~g} / \mathrm{kg}$ diet $)$ from a strain of the microalga Dunaliella bardawil. The dry material contained phytoene at $2 \%$ and phytofluene at $0.1 \%$. The largest accumulation of phytoene was found in liver, followed by adrenals. The levels in other tissues like brain, heart, lung, kidney and spleen were considerably lower [120].

In order to gain insight into the tissue distribution of phytoene, phytofluene and lycopene, male Fisher 344 rats were fed a diet containing $10 \%$ of tomato powder with similar concentrations of the three carotenoids $(0.015,0.012$, and $0.011 \mathrm{~g} / \mathrm{kg}$ diet, respectively). At the end of the study the major plasma carotenoid was phytoene, followed by phytofluene. The hepatic phytofluene concentration was found to be ca. 1.5-fold higher than that of the other two. Contrastingly, phytoene levels were the lowest and lycopene levels the highest in the prostate lobes and seminal vesicles. Different accumulation patterns were also found in other tissues. The authors concluded that the relative distribution of the three carotenoids was distinct in liver and androgen-sensitive tissues and that phytoene could be absorbed more readily than lycopene [121].

Another study evaluated the effect of tomato powders in the accumulation of their major carotenoids in male Copenhagen rats. It was observed that different carotenoid levels in the powders resulted in distinct hepatic accumulations. Thus, the use of a tomato powder with over twice the amount of lycopene relative to the standard powder resulted in significant higher lycopene accumulation and significantly lower phytoene and phytofluene accumulation relative to the standard. The animals supplementation with a third type of powder with a higher total carotenoid content with significantly more phytoene and phytofluene but not enhanced lycopene accumulated significantly more hepatic colorless carotenoids but the same quantity of lycopene relative to the 
standard powder-fed rats. The analysis of the results seem to indicate that there may be interaction between the three carotenoids in the processes related to their bioavailability [122].

The effect of supplementing the diet of male Sprague-Dawley with a tomato extract on high-fat-diet related liver inflammation, lipid profiles and carcinogenesis has been recently studied. The animals were fed either a control diet (35\% fat, CD) or a high fat diet (71\% fat, HFD) with or without the tomato supplementation. The tomato extract contained lycopene, phytoene and phytofluene in a ratio 1.0:0.6:0.3. Up to 5 different isomers of phytofluene were detected in the extract. The plasma levels of lycopene were the lowest and those of phytoene the highest in both CD and HFD groups. More specifically, the plasma levels of phytoene and phytofluene were ca. 7-fold and 3.5-fold greater respectively, than those of lycopene in the animals receiving the $C D$ plus the tomato supplementation. In the case of the group receiving HFD and tomato supplementation the concentrations of PT and PTF were even higher relative to those of lycopene (ca. 34-fold and 9-fold, respectively). The hepatic levels of lycopene were the lowest and those of PT the highest in the two groups. Interestingly the levels of hepatic lycopene in the rats receiving the HFD plus tomato were significantly higher relative to the group receiving $C D$ plus tomato. It was concluded that there are differences in the factors governing the bioavailability of the three carotenoids and that the effect of differences in their chemical structure, mainly geometrical isomerism and number of conjugated double bonds, needs more research [123].

\section{Ferrets}

Most of the studies dealing with the bioavailability of phytoene and phytofluene in laboratory animals were carried out in rats. However, ferrets are known to absorb carotenoids more efficiently. Both phytoene ((15Z)- and all-E-phytoene) and phytofluene (up to 5 isomers), along with several geometrical isomers of both $\beta$-carotene and lycopene have been reported to accumulate in the lungs of male ferrets receiving a diet supplemented with a tomato extract [22].

\section{Mongolian gerbils}

A recent study has been carried out in order to gain insight into the different absorption and accumulation of lycopene and phytotene. In brief, Mongolian gerbils $(n=56)$ were fed a diet containing tomato powder for 26 days. Subsequently, the animals were given either a single cottonseed oil vehicle dose or phytoene or lycopene in cotton oil. Lycopene was found to be predominant in liver, spleen, testes and prostate-seminal vesicle in the animals receiving just the vehicle. Phytoene was the major carotenoid in serum and adipose tissue, whereas phytofluene was predominant in adrenals and lungs. The dosing with phytoene and lycopene indicated that the former was more bioavailable and had a slower clearance than the latter. To gain further insight into differences in the accumulation of both carotenoids, labeled carotenoids ((14)C-phytoene or (14)C-lycopene) was supplied to animals fed tomato powder. Interestingly, it was observed that almost all extra-hepatic tissue accumulated more radioactivity after labeled-phytoene than labeled-lycopene dosing. Altogether, the data from this interesting study confirmed that there are important differences between these two carotenoids in bioavailability, tissue accumulation and clearance [124].

\section{Humans}

\section{Presence in human biological fluids}

Interestingly, a study showed that the plasma levels of phytofluene, as well as of lycopene, lutein/zeaxanthin and vitamin E were similar in both smoking and non-smoking Scottish males, while those of the provitamin A carotenoids ( $\alpha$-carotene, $\beta$-carotene and $\beta$-cryptoxanthin) and vitamin $C$ were lower in the first group [125].

Both phytoene and phytofluene were found to be present in the serum and breast milk of lactating women $(n=3)$, the contents being lower in the latter. The reported levels of phytofluene were higher in both biological fluids, between 7.8 and $13.9 \mu \mathrm{g} / \mathrm{dL}$ in serum and 0.4 and $1.4 \mu \mathrm{g} / \mathrm{dL}$ in milk. In the case of phytoene the serum levels ranged between 1.9 and $3.3 \mu \mathrm{g} / \mathrm{dL}$ and those found in milk where $0.1 \mu \mathrm{g} / \mathrm{dL}$ [90].

In a thorough randomized crossover design study, 9 women and 7 men were administered lycopene-rich tomato juice ( $476 \mathrm{~mL} /$ day; $74.9 \mathrm{mg}$ of lycopene, $5.11 \mathrm{mg}$ of phytofluene and $5.76 \mathrm{mg}$ of phytoene/day), oleoresin soft-gel capsules (4 capsules/day; $75.4 \mathrm{mg}$ of lycopene, $4.91 \mathrm{mg}$ of phytofluene and $4.40 \mathrm{mg}$ of phytoene/day), lycopene beadlets (15 capsules/day; $70.2 \mathrm{mg}$ of lycopene, $3.67 \mathrm{mg}$ of phytofluene and $2.46 \mathrm{mg}$ of phytoene/day) or placebo for 4 weeks each while consuming self-selected diets. The reported baseline plasma levels ranged between 0.54 and $0.60 \mu \mathrm{M}$ in the case of lycopene, 0.27 and $0.30 \mu \mathrm{M}$ in the case of phytofluene and 0.10 and $0.11 \mu \mathrm{M}$ in the case of phytoene. Averaging the four treatments, it was found that the highest proportion of the three carotenes (ranging from $65 \%$ in phytofluene to $76 \%$ in phytoene and lycopene) was found in LDL. This agreed well with the accepted observation that carotenes are mainly found in those lipoproteins. Interestingly, the authors observed subtle differences in the distribution pattern of phytofluene and phytoene among lipoproteins compared to the other major circulating carotenes (lycopene, $\alpha$-carotene and $\beta$-carotene). Thus their relative contents were found to be higher in VLDLs and lower in both LDLs and HDLs. The changes relative from baseline ranged between -0.16 (placebo) and $0.24 \mu \mathrm{M}$ (oleoresin) in the case of lycopene, -0.08 (placebo) and $0.45 \mu \mathrm{M}$ (juice) in the case of phytofluene and -0.02 (placebo) and $0.19 \mu \mathrm{M}$ (juice) in the case of phytoene. In sum it was concluded that the plasma concentration of the three compounds were significantly increased with the three carotenoid sources tested [126]. In relation to this study it is to be noted that the daily intake of the three carotenoids was higher than those achievable by a "normal diet", specially true in the case of lycopene, as it can be noticed by comparing these data with the reported by Biehler et al. [115].

In a study performed to assess changes in the plasma levels of carotenoids and other compounds, 23 male healthy individuals were subjected to a 2-week carotenoid depletion period and then supplemented with a series of carotenoid rich products $(330 \mathrm{~mL}$ tomato juice for 2 weeks, then $330 \mathrm{~mL}$ carrot juice for 2 weeks and then $10 \mathrm{~g}$ spinach powder for 2 weeks). During the study the individuals maintained mostly their usual diets, although they were asked to avoid a series of carotenoid-rich products. The average levels of phytofluene were $0.14 \mathrm{nmol} / \mathrm{mL}$ and 0.12 at the beginning and the end of the washout period, respectively. In the case of phytoene, such mean levels were 0.14 and 0.09 , which could indicate that the depletion of phytoene is faster under the conditions tested. At the end of the tomato and carrot supplementation periods (both sources containing the two carotenoids) the plasma levels peaked, reaching concentrations of $0.44 \mathrm{nmol} / \mathrm{mL}$ for phytoene and $0.55 \mathrm{nmol} / \mathrm{mL}$ for phytofluene. After the 2 weeks of supplementation with spinach (which is not a good source of phytoene and phytofluene) their plasma level decreased noticeably (0.29 and $0.26 \mathrm{nmol} / \mathrm{mL}$ for phytoene and phytofluene, respectively) [127].

The effect of watermelon consumption in the plasma levels of lycopene and other carotenoids was studied by Edwards et al. [128]. The plasma levels of carotenoids in 23 volunteers following supplementation with watermelon juice in a 19-week crossover study was studied. The volunteers were subjected to three 3-week 
supplementation periods preceded by lycopene depletion periods ranging from 2 to 4 weeks. All consumed a watermelon juice providing $20.1 \mathrm{mg} /$ day lycopene (W-20 treatment). After a washout period, the volunteers were provided either watermelon supplying $40.2 \mathrm{mg} /$ day lycopene (W-40 treatment) or tomato juice supplying $18.4 \mathrm{mg} /$ day lycopene ( $\mathrm{T}-20$ treatment). The authors observed that both phytofluene and phytoene levels doubled after the T-20 tomato treatment. Phytoene was found to be bioavailable from the watermelon juice, but particularly from the tomato juice. The plasma levels of phytofluene were observed to increase only for the $\mathrm{T}-20$ supplementation, not for the watermelon juices treatments [128].

The bioavailability of lycopene and phytofluene from a tomato paste and a food formulation where the carotenoids were entrapped in whey proteins ("lactolycopene") was compared in 36 volunteers ( 13 men and 23 women) by Richelle et al. [129]. The individuals were allocated in random to one of three treatment groups $(25 \mathrm{mg} /$ day lycopene and $1.6 \mathrm{mg}$ /day phytofluene from tomato paste, $25 \mathrm{mg} /$ day lycopene and $1.98 \mathrm{mg}$ /day phytofluene from lactolycopene or placebo of whey proteins). They followed the treatments for 8 weeks while eating their self-selected diets with restriction of lycopene-rich foods. Previously they were subjected to a 3-week lycopene washout period. The daily supplementation resulted in significant increases in the plasma levels of phytofluene after the 8-week interventions. The increase was lower with lactolycopene than with tomato paste $(0.23$ and $0.33 \mu \mathrm{mol} / \mathrm{L}$ increases, respectively) [129].

In another interesting study 36 healthy volunteers were randomly allocated to three groups $(n=12)$, who ingested either synthetic lycopene in beadlets (two hard shell capsules per day; $5.1 \mathrm{mg} /$ capsule), a commercial tomato extract in soft gel capsules ( 2 capsules per day; $4.9 \mathrm{mg}$ lycopene, $0.4 \mathrm{mg}$ phytofluene, $0.5 \mathrm{mg}$ phytoene, and $0.2 \mathrm{mg} \beta$-carotene/capsule) or a commercial tomato-based drink (250 $\mathrm{mL}$ two times per day; $4.1 \mathrm{mg}$ lycopene, $1.6 \mathrm{mg}$ [130] phytofluene, $2.3 \mathrm{mg}$ phytoene, and $0.2 \mathrm{mg} \beta$-carotene $/ 250 \mathrm{~mL}$ ). Different isomers of phytoene and phytofluene were detected in the two latter products. The supplementation lasted 12 weeks. The basal plasma levels of the carotenoids in the three groups ranged between 0.28 and $0.37 \mathrm{nmol} / \mathrm{mL}$ (lycopene), 0.27 and $0.44 \mathrm{nmol} / \mathrm{mL}$ (phytofluene) and 0.06 and $0.07 \mathrm{nmol} / \mathrm{mL}$ (phytoene). At the end of the study the lycopene levels ranged between 0.55 and $0.88 \mathrm{nmol} / \mathrm{mL}$, The phytofluene plasma levels increased from $0.44 \mathrm{nmol} / \mathrm{mL}$ at $t=0$ to $0.94 \mathrm{nmol} / \mathrm{mL}$ in the tomato extract group and from 0.27 to $0.87 \mathrm{nmol} / \mathrm{mL}$ in the tomato drink one. The effect of the interventions in the serum phytoene levels were less pronounced but still noticeable (ca. 2-fold) [130].

Increases in the plasma levels of phytoene, phytofluene and lycopene upon supplementation have also been reported in another studies, in which increases in their levels in lymphocytes were also observed [131].

\section{Presence in human tissues}

The information about the presence of phytoene and phytofluene in human tissues is very limited. Phytoene and phytofluene have been reported to accumulate in liver, lung, breast, cervix, prostate, colon and skin in the range of $\mathrm{ng} / \mathrm{g}$ in samples from very few individuals $(n=3-5)$. The patterns of deposition in such tissues was not consistent. Higher levels of phytofluene over phytoene were found in all except lung and skin (reviewed in [132]).

The production and use of isotopically labeled colorless carotenoids $[38,133,134]$ is expected to shed light in the factors involved in their bioavailability, many of which remain obscure. They are specially useful to study the fate of a dose of the compound in individuals already containing an endogenous pool of it, which is the common situation as carotenoids are part of any normal diet and it is difficult to deplete them with the washout periods traditionally used in interventions.

\section{Possible biological actions}

There are studies of different nature (in vitro, using laboratory animals or in humans) that indicate that the colorless carotenoids phytoene and phytofluene may be involved, in their own or in conjunction with other food constituents, in biological actions that could provide health benefits. At this point it is important to consider that it is necessary to distinguish between physiological and pharmacological levels in order to better interpret the results reported in the studies. The concentrations reported in the previous sections ("Presence in human biological fluids" and "Presence in human tissues") can be very useful for this purpose. An excellent review on nutritional aspects related to phytoene and phytofluene including potential biological effects has been recently published [157].

\section{Cancer}

Skin

One of the first reports on the possible antitumor activity of carotenoids in general was probably the published study by Matthews-Roth [135]. In this, the administration of phytoene was observed to delay the skin tumors appearance and reduce their number in mice that were induced the tumors with UV-B light.

\section{Prostate}

The fist report on the possible beneficial effect of colorless carotenoids in prostate cancer is probably the published study by Kotake-Nara et al. [136]. In such investigation the effect of 15 carotenoids, including phytoene and phytofluene, on the viability of PC-3, DU 145 and LNCaP human prostate cancer cell lines was assessed. Phytofluene, but not phytoene, was shown to reduce the viability of cancer cells when supplemented at $20 \mu \mathrm{M}$ in the medium for $72 \mathrm{~h}$ [136].

Very interestingly, in a study in which a prostate cancer model was used, a significantly lower risk of death from that malignancy was observed in rats fed tomato powder (containing PT and PTF and other compounds in addition to lycopene) but little effect was observed in the rats fed pure LYC. The authors concluded that the intake of tomato powder but not only lycopene inhibited prostate carcinogenesis and that there were other compounds in tomato that modified the carcinogenesis [137].

Phytofluene and lycopene on their own or as part of tomato may have a beneficial role in prostate cancer by reducing serum testosterone, as demonstrated in a study using F344 rats [138]. It has been observed that castration or lower androgen status resulted in higher levels of both carotenoids in plasma, prostate and seminal vesicles of the rats receiving doses of the carotenoids. Interestingly, these responses were not consistent when tomato powder was administered. The authors hypothesized that, since oxidative stress events associated to the metabolism of androgens could lead to the consumption of carotenoids, alterations in such metabolism could have an impact in their levels [138].

\section{Leukemia}

The effect of both acyclic carotenes (phytoene, phytofluene, $\zeta$ carotene and lycopene) and some oxidation products of them in the proliferation of human promyelocytic leukemia cells was studied using in vitro HL-60 cell line cultures [139]. The addition of $\zeta$ carotene and phytofluene at $10 \mu \mathrm{M}$ into the culture medium led to inhibition of cell growth relative to the control, the effect being markedly higher in the case of the former (ca. $4 \%$ cell density of the 
control vs ca. 23 in the case of phytofluene). Interestingly, they were not detected in the cells indicating that they were highly unstable under the conditions tested. An interesting finding of this study was that oxidation mixtures of each tested carotenoid (containing also some residual intact carotenoid) inhibited the growth of the cells. The inhibition was greater compared to the obtained when the respective parent carotenoids were tested. As an example, the oxidation mixture of phytofluene at $6 \mu \mathrm{M}$ inhibited cell growth to ca. $8 \%$, while pure phytofluene at the same concentration inhibited it to a much lower extent (ca. 68\%). It is to be noted that the effect of mixtures of oxidation products of phytoene was not evaluated [139].

\section{Breast and endometrial cancer}

The effect of phytoene, phytofluene and other carotenoids in the inhibition of cell proliferation and estrogen transcriptional activity induced by estrogens ( $17 \beta$-estradiol and soy phytoestrogens) was studied by Hirsch et al. [140]. To this end, cell lines of breast (MCF-7 and T47D) and endometrial (ECC-1) hormone-dependent cancer cells were treated with increasing amounts of either $17 \beta$ estradiol or the soy phytoestrogen genistein in presence or absence of the carotenoids. Both phytoene and phytofluene at a concentration of $4-6 \mu \mathrm{M}$ in the medium were shown to inhibit the proliferation of the cells induced by the tested estrogens. Additionally, all the carotenoids evaluated inhibited the estrogen-induced transactivation of the estrogen response element (ERE) [140].

An ingenious approach to study the effects of carotenoids in events related to carcinogenesis is to transfect the animal cells with carotenogenic genes so that the carotenoids are formed in the cells. As an example, a bacterial phytoene synthase gene was introduced in mouse embryonic fibroblasts (NIH3T3). The production of phytoene led by the transgenic cells led to protection against oxidative stress (assessed by measuring phospholipid peroxidation induced by oxidative stress) and malignant transformation. The authors stated that the term "bio-chemoprevention" ("biotechnology-assisted method for cancer chemoprevention") may be applicable in this context as the transgenic cells acquired resistance against carcinogenesis [141].

\section{Oxidation}

The colorless carotenoids might protect LDL from oxidation according to the results of an in vitro study in which oxidized human LDLs were treated with phytoene and phytofluene from the microalgae $D$. bardawil. The protection of these particles from oxidation is important as LDL oxidation is thought to be a key event in the pathogenesis of cardiovascular disease [142].

The effect of phytoene, phytofluene and lycopene on the antioxidant response element (ARE) and nuclear factor E2-related factor (Nrf2) was studied by Ben-Dor et al. [143]. Both ARE and Nrf2 are involved in the control of the expression of phase II enzymes, some of which like $\operatorname{NAD}(\mathrm{P}) \mathrm{H}$ :quinone oxidoreductase (NQO1) and $\gamma$ glutamylcysteine synthetase (GCS) have been shown to be inducible. These phase II enzymes are beneficial as they can detoxify harmful compounds by converting them to hydrophilic derivatives that can be readily excreted. A mixture of phytoene and phytofluene (70:30) (4-6 $\mu \mathrm{M})$ was shown to transactivate ARE Sequences of GCS and NQO1genes in transfected MCF-7 and HepG2 cell lines, although the effect was noticeably less pronounced as that caused by lycopene $(2-4 \mu \mathrm{M})$. It was also observed that both the mixture of colorless carotenoids and lycopene decreased the intracellular levels of reactive oxygen species at comparable levels [143].

The effect of the intake of a tomato drink providing lycopene, phytoene and phytofluene in lymphocytes subjected to oxidative stress has been evaluated [131]. The daily supplementation with $250 \mathrm{~mL}$ of the drink (which provided approximately $6 \mathrm{mg}$ lyco- pene, $4 \mathrm{mg}$ phytoene, $3 \mathrm{mg}$ phytofluene, $1 \mathrm{mg} \beta$-carotene and $1.8 \mathrm{mg} \alpha$-tocopherol) led to significant increases in the plasma levels of the carotenoids (specifically 1.6-fold for phytofluene and ca. 2 -fold for phytoene) and their content in lymphocytes (1.8-fold higher in the case of phytofluene and 2.6-fold higher in the case of phytoene). The consumption of the drink was also shown to significantly decrease the DNA damage (assessed by the comet assay) of lymphocytes under oxidative stress, suggesting that a realistic intake of carotenoids from tomato products can protect the cell against oxidation [131].

\section{Light-induced skin damage}

The protective effects of colorless carotenoids against light caused lesions in the skin were already postulated 30 years ago. More specifically, a study showed that large doses of phytoene injected to guinea pigs for 2 weeks could somewhat protect the animals from UV-induced erythema in comparison to those receiving placebo [144].

Carotenoids, including phytoene and phytofluene, are known to accumulate in human skin (in the range of $\mathrm{nmol} / \mathrm{g}$ wet tissue), preferably in the forehead, palm of the hand and dorsal skin. In fact, it is well known that the intake of large quantities of carotenoids can produce carotenodermia, a phenomenon characterized by changes in the skin color to yellow or yellow-orange. Excessive exposure to light can result in disorders of different magnitude, from erythemas to cancer. Depending on the wavelength range the light reaches different locations of the skin. Thus, UVA (320$400 \mathrm{~nm}$ ) reaches the entire dermis but UVB $(280-320 \mathrm{~nm})$ reaches the epidermis in the main. As an example, excessive UVB radiation can cause erythemas (also known as sunburn). Other skin disorders caused by light, like photooxidation are mediated by reactive oxygen species and can lead to premature skin aging or cancer, among other disorders (reviewed in [145]). As stated earlier, phytoene and phytofluene are rarities among carotenoids because they absorb UV light. In this sense it is reasonable to expect that they could contribute to photoprotection by absorbing such damaging light. In this sense, there is evidence that they could protect from UVlight-induced erythema [130]. In this study, volunteers were supplemented with synthetic lycopene, a tomato extract or a tomato-based drink (all of them supplying approximately about $10 \mathrm{mg}$ lycopene/day) for 12 weeks. Such intervention led to significant increases in plasma and skin carotenoid levels and to prevention of erythema-induced formation in all groups. Interestingly, the protective effect was more pronounced when the tomato based products were used, suggesting that phytofluene and phytoene may have contributed to the effect [130].

Although the dietary protection attributable to the intake of carotenoids and other food constituents could not be comparable to that provided by sunscreens, the enhancement of basal protection can be important for the long-term defense from skin disorders caused by light [146].

The effects of ubiquinone (coenzyme Q10) and colorless carotenoids on the inflammation of human dermal fibroblasts subjected to UV light have been investigated in order to assess possible synergistic effects [147]. To this end dermal fibroblast cells from human neonatal foreskin were cultured in vitro, subjected to either UV light or interleukin 1 (IL-1) and subsequently incubated with either the coenzyme, phytoene plus phytofluene (final concentration of $15 \mu \mathrm{g} / \mathrm{mL}$ ) or combinations of the coenzyme and the carotenoids. The exposure to UV radiation or IL-1 increased the production of several inflammatory mediators by the cells. The combination or colorless carotenoids and the coenzyme was shown to enhance the inflammatory response. Interestingly, phytoene and phytofluene seemed to protect coenzyme Q10 from oxidation by hypochlorite [147]. 


\section{Lipid metabolism}

The effects of supplementing tomato extract (TE) against high-fat-diet related hepatic inflammation and lipid profiles and carcinogenesis has been recently investigated in rats. Four groups of rats were treated with a liver carcinogen and then provided a control diet (35\% fat, CD) or high fat diet (71\% fat, HFD) in the presence or absence of a tomato extract $(50 \mathrm{mg} / \mathrm{kg}$ body weight per day) during 6 weeks. According to the manufacturer, the tomato extract contained approximately 6\% LYC, 1\% PT and 1\% PTF. The intake of the tomato extract resulted in higher phytoene and phytofluene plasma. More especifically, The plasma levels of PT were approximately 7 -fold higher relative to lycopene in the rats receiving $\mathrm{CD}+\mathrm{TE}$ and 34-fold higher in the ones receiving HFD + TE. The plasma levels of PTF were 3.5-fold and 9-fold higher relative to LYC in $\mathrm{CD}+\mathrm{TE}$ and HFD + TE rats, respectively. Independently of the amount of fat in the diet the phytoene hepatic levels were the highest and the lycopene levels the lowest. This was associated to a decrease of plasma total cholesterol in tomato supplemented CD and HFD animals. Contrastingly, the supplementation with the extract resulted in a significant increase in the hepatic levels of all the lipids evaluated (total cholesterol, triglycerides and free fatty acids) except those of free fatty acids in animals on CD. Changes in the expression of genes encoding proteins involved in lipid metabolism, like acetyl-CoA carboxylase (ACC-1), diacylglycerol acyltransferase (DGAT), carnitine palmitoyltransferase (CPT1 ), the peroxisome proliferator-activated receptor gamma (PPAR $\gamma$ ) and the sterol-regulatory element binding protein (SREBP-1), were observed. The tomato supplementation in CD and HFD-fed animals also led to significant increases in the mRNA levels of cluster of differentiation 36 (CD36), a type of class B scavenger receptor, which intervenes in the uptake of plasma FFA by the liver. On the other hand, the tomato supplementation significantly decreased the multiplicity of inflammatory and altered hepatic foci in the liver of HFD-fed rats [123]. Contrastingly, no changes in inflammatory markers were observed in a study referred to before where gerbils were fed tomato powder plus lycopene or phytoene [124].

The peroxisome proliferator-activated receptors (PPARs) belong to the nuclear receptor superfamily and play key roles in lipid metabolism, insulin resistance, inflammation and other processes [148]. The capacity of tomato fruit extracts and tomato components to activate PPAR $\gamma$ has been recently evaluated by using a reporter cell line [149]. Up to thirty tomato compounds were assayed, including seven carotenoids. While phytoene was found to be inactive, phytofluene at $1 \mu \mathrm{M}$ and $10 \mu \mathrm{M}$ was observed to activate the receptor at comparable levels in comparison to lycopene [149].

In conclusion, it can be stated that phytoene and phytofluene are common dietary carotenoids. They are present together with lycopene in tomatoes and derivatives and other foods. Besides they are also present in widely consumed plant foods like oranges, mandarins and carrots, among others. In fact, their intake may be higher than that of lycopene. Interestingly, they are consistently found in human plasma, milk and tissues and there are evidences of different nature associating them with biological actions, although causality needs to be established. In this regard, further studies on them from different standpoints are encouraged.

\section{Acknowledgments}

A.J.M.M. acknowledges funding from the Andalusian Coundil of Economy, Innovation, Science and Employment (project ref. CAROTINCO-P12-AGR-1287), the Spanish State Secretariat of Research, Development and Innovation (Ministry of Economy and Competitiveness, project ref. AGL2012-37610, co-funded by FEDER) and the National Program for the Mobility of Human Resources (ref.
JC-2009-00176). The authors are members of the IBERCAROT network, funded by CYTED (ref. 112RT0445).

\section{References}

[1] T. Nakayama, C.O. Chichester, A. Lukton, G. Mackinney, Arch. Biochem. Biophys. 66 (2) (1957) 310-315.

[2] L. Zechmeister, B.K. Koe, J. Am. Chem. Soc. 76 (11) (1954) 2923-2926.

[3] J.W. Porter, Arch. Biochem. Biophys. (1953) 252

[4] B.K. Koe, L. Zechmeister, Arch. Biochem. Biophys. 46 (1) (1953) 100-104.

[5] V. Wallace, J.W. Porter, Arch. Biochem. Biophys. 36 (2) (1952) 468-472.

[6] G. Mackinney, W.E. Fratzke, Ind. Eng. Chem. 19 (8) (1947) 614-615.

[7] L. Zechmeister, A. Sandoval, J. Am. Chem. Soc. 68 (2) (1946) 197-201.

[8] G. Britton, S. Liaaen-Jensen, H. Pfander, Carotenoids. Handbook, Birkhäuser, Basel, Switzerland, 2004.

[9] G. Britton, FASEB J. 9 (1995) 1551-1558.

[10] G. Britton, UV/visible spectroscopy, in: G. Britton, S. Liaaen-Jensen, H. Pfander (Eds.), Carotenoids Volume 1B: Spectroscopy, Birkhäuser, Basel, Switzerland, 1995, pp. 13-62.

[11] D.B. Rodriguez-Amaya, A guide to carotenoid analysis in foods, in: Life Sciences, ILSI Press, Washington, D.C., 2001.

[12] A.J. Meléndez-Martínez, G. Britton, I.M. Vicario, F.J. Heredia, Food Chem. 101 (3) (2007) 1145-1150.

[13] B.H. Davies, Carotenoids, in: T.W. Goodwin (Ed.), Chemistry and Biochemistry of Plant Pigments, second ed., Academic Press, London, United Kingdom, 1976, pp. 38-165.

[14] A. Martínez, C.M. Stinco, A.J. Meléndez-Martínez, J. Phys. Chem. B 118 (33) (2014) 9819-9825.

[15] V. Böhm, N.L. Puspitasari-Nienaber, M.G. Ferruzzi, S.J. Schwartz, J. Agric. Food Chem. 50 (1) (2002) 221-226.

[16] A. Schieber, R. Carle, Trends Food Sci. Technol. 16 (9) (2005) 416-422.

[17] K. Hu, C. Liu, H. Ernst, N.I. Krinsky, R.M. Russell, X. Wang, J. Biol. Chem. 281 (28) (2006) 19327-19338.

[18] A. Than, P.M. Bramley, B.H. Davies, A.F. Rees, Int. J. Vitam. Nutr. Res. 11 (1954) (1972) 3187-3192.

[19] R. Powls, G. Britton, Arch. Microbiol. 115 (2) (1977) 175-179.

[20] H.H. Schmitz, C. Emenhiser, S.J. Schwartz, J. Agric. Food Chem. 43 (5) (1995) $1212-1218$.

[21] A.J. Meléndez-Martínez, P.D. Fraser, P.M. Bramley, Phytochemistry 71 (10) 2010) 1104-1114

[22] A.J. Meléndez-Martínez, C.M. Stinco, C. Liu, X.D Wang, Food Chem. 138 (2-3) (2013) 1341-1350.

[23] A.J. Meléndez-Martínez, M. Paulino, C.M. Stinco, P. Mapelli-Brahm, X.-D Wang. J. Agric. Food Chem. 62 (51) (2014) 12399-12406.

[24] P.D. Fraser, S. Romer, C.A. Shipton, P.B. Mills, J.W. Kiano, N. Misawa, et al. Proc. Natl. Acad. Sci. USA 99 (2) (2002) 1092-1097.

[25] M. Salvini, A. Bernini, M. Fambrini, C. Pugliesi, J. Plant Physiol. 162 (2005) 479-484.

[26] S. Lu, L. Li, J. Integr. Plant Biol. 50 (7) (2008) 778-785.

[27] C.I. Cazzonelli, B.J. Pogson, Trends Plant Sci. 15 (5) (2010) 266-274.

[28] G. Britton, R. Powls, Phytochemistry 16 (8) (1977) 1253-1255.

[29] G. Sandmann, Arch. Biochem. Biophys. 483 (2) (2009) 169-174.

[30] G. Sandmann, Eur. J. Biochem. 223 (1994) 7-24.

[31] J. Paniagua-Michel, J. Olmos-Soto, M.A. Ruiz, Methods Mol. Biol. 892 (2012) $1-12$.

[32] S. Takaichi, M. Mochimaru, Cell. Mol. Life Sci. 64 (19-20) (2007) 2607-2619.

[33] G.E. Bartley, P.A. Scolnik, J. Biol. Chem. 264 (22) (1989) 13109-13113.

[34] G.A. Armstrong, M. Alberti, F. Leach, J.E. Hearst, Mol. Gen. Genet. 216 (2-3) (1989) 254-268.

[35] A. Hausmann, G. Sandmann, Fungal Genet. Biol. 30 (2) (2000) 147-153.

[36] S. Steiger, Y. Jackisch, G. Sandmann, Arch. Microbiol. 184 (4) (2005) 207-214.

[37] T. Tsuchiya, S. Takaichi, N. Misawa, T. Maoka, H. Miyashita, M. Mimuro, FEBS Lett. 579 (10) (2005) 2125-2129.

[38] C.H. Lu, J.H. Choi, J. Agric. Food Chem. 59 (18) (2011) 9996-10005.

[39] S. Römer, P.D. Fraser, J.W. Kiano, C.A. Shipton, N. Misawa, W. Schuch, et al., Nat. Biotechnol. 18 (6) (2000) 666-669.

[40] J. Breitenbach, G. Sandmann, Planta 220 (5) (2005) 785-793.

[41] T. Isaacson, I. Ohad, P. Beyer, J. Hirschberg, Plant Physiol. 136 (4) (2004) $4246-4255$.

[42] F. Li, C. Murillo, E.T. Wurtzel, Plant Physiol. 144 (2) (2007) 1181-1189.

[43] T. Isaacson, G. Ronen, D. Zamir, J. Hirschberg, Plant Cell 14 (2002) 333-342.

[44] D. Chamovitz, N. Misawa, G. Sandmann, J. Hirschberg, FEBS Lett. 296 (3) (1992) 305-310.

[45] I. Martínez-Férez, B. Fernández-González, G. Sandmann, A. Vioque, Biochim. Biophys. Acta - Gene Struct. Expr. 1218 (2) (1994) 145-152.

[46] C. Schneider, P. Böger, G. Sandmann, Protein Expr. Purif. 10 (2) (1997) 175179.

[47] N.-U. Frigaard, J.A. Maresca, C.E. Yunker, A.D. Jones, D.A. Bryant, J. Bacteriol. 186 (16) (2004) 5210-5220.

[48] D. Chamovitz, I. Pecker, G. Sandmann, P. Böger, J. Hirschberg, Z. Naturforsch C. 45 (5) (1990) 482-486.

[49] M. Lohr, C.-S. Im, A.R. Grossman, Plant Physiol. 138 (1) (2005) 490-515.

[50] D. Tran, J. Haven, W.-G. Qiu, J.E.W. Polle, Planta 229 (3) (2009) 723-729.

[51] F. Li, R. Vallabhaneni, J. Yu, T. Rocheford, E.T. Wurtzel, Plant Physiol. 147 (3) (2008) 1334-1346. 
[52] R. Welsch, F. Wüst, C. Bär, S. Al-Babili, P. Beyer, Plant Physiol. 147 (1) (2008) $367-380$.

[53] N. Chaudhary, A. Nijhawan, J.P. Khurana, P. Khurana, Mol. Genet. Genomics 283 (1) (2010) 13-33.

[54] C.A. Howitt, C.R. Cavanagh, A.F. Bowerman, C. Cazzonelli, L. Rampling, J.L. Mimica, et al., Funct. Integr. Genomics 9 (3) (2009) 363-376.

[55] F. Li, R. Vallabhaneni, E.T. Wurtzel, Plant Physiol. 146 (3) (2008) 1333-1345.

[56] B.M. Lange, M. Ghassemian, Plant Mol. Biol. 51 (6) (2003) 925-948.

[57] C.P. Moehs, L. Tian, K.W. Osteryoung, D. Dellapenna, Plant Mol. Biol. 45 (3) (2001) 281-293.

[58] M. Kuntz, S. Römer, C. Suire, P. Hugueney, J.H. Weil, R. Schantz, et al., Plant J. 2 (1) (1992) 25-34.

[59] Z. Karvouni, I. John, J.E. Taylor, C.F. Watson, A.J. Turner, D. Grierson, Plant Mol. Biol. 27 (6) (1995) 1153-1162.

[60] M. Schledz, S. Al-Babili, J.V. Lintig, H. Haubruck, S. Rabbani, H. Kleinig, et al., Plant J. 10 (5) (1996) 781-792.

[61] M. Busch, A. Seuter, R. Hain, Plant Physiol. 128 (2) (2002) 439-453.

[62] G.E. Bartley, P.A. Scolnik, J. Biol. Chem. 268 (34) (1993) 25718-25721.

[63] R.G. Fray, D. Grierson, Plant Mol. Biol. 22 (4) (1993) 589-602.

[64] P.D. Fraser, M.R. Truesdale, C.R. Bird, W. Schuch, P.M. Bramley, Plant Physiol. 105 (1994) 405-413.

[65] G. Ronen, M. Cohen, D. Zamir, J. Hirschberg, Plant J. 17 (4) (1999) 341-351.

[66] C.E. Gallagher, P.D. Matthews, F. Li, E.T. Wurtzel, Plant Physiol. 135 (3) (2004) 1776-1783.

[67] F. Li, O. Tzfadia, E.T. Wurtzel, Plant Signal. Behav. 4 (3) (2009) 208-211.

[68] M. Shumskaya, L.M.T. Bradbury, R.R. Monaco, E.T. Wurtzel, Plant Cell 24 (9) (2012) 3725-3741.

[69] M. Shumskaya, E.T. Wurtzel, Plant Sci. 208 (2013) 58-63.

[70] P.D. Fraser, P.M. Bramley, Prog. Lipid Res. 43 (3) (2004) 228-265.

[71] G. Farré, C. Bai, R.M. Twyman, T. Capell, P. Christou, C. Zhu, Trends Plant Sci. 16 (10) (2011) 532-540.

[72] G. Giuliano, R. Tavazza, G. Diretto, P. Beyer, M.A. Taylor, Trends Biotechnol. 26 (3) (2008) 139-145.

[73] P.D. Fraser, E.M.A. Enfissi, J.M. Halket, M.R. Truesdale, D. Yu, C. Gerrish, et al., Plant Cell 19 (10) (2007) 3194-3211.

[74] F.P. Robertson, P.K. Koistinen, C. Gerrish, J.M. Halket, R.K.P. Patel, P.D. Fraser, et al., J. Exp. Bot. 63 (16) (2012) 6035-6043.

[75] X.D. Ye, S. Al Babili, A. Kloti, J. Zhang, P. Lucca, P. Beyer, et al., Science 287 (5451) (2000) 303-305.

[76] J.A. Paine, C.A. Shipton, S. Chaggar, R.M. Howells, M.J. Kennedy, G. Vernon, et al., Nat. Biotechnol. 23 (4) (2005) 482-487.

[77] P. Hugueney, S. Romer, M. Kuntz, B. Camara, Eur. J. Biochem. 209 (1) (1992) 399-407.

[78] I. Pecker, D. Chamovitz, H. Linden, G. Sandmann, J. Hirschberg, Proc. Natl. Acad. Sci. U.S.A. 89 (1992) 4962-4966.

[79] Li. Zhou-Hui, Plant Mol. Biol. 30 (2) (1996) 269-279.

[80] S. Al-Babili, J.V. Lintig, H. Haubruck, P. Beyer, Plant J. 9 (5) (1996) 601-612.

[81] G.E. Bartley, P.V. Viitanen, I. Pecker, D. Chamovitz, J. Hirschberg, P.A. Scolnik Proc. Natl. Acad. Sci. U.S.A. 88 (15) (1991) 6532-6536.

[82] H.W. Kuemmel, L.H. Grimme, Z. Naturforsch. C Biosci. (1975) 333-336

[83] D. Chamovitz, I. Pecker, J. Hirschberg, Plant Mol. Biol. 16 (6) (1991) 967-974.

[84] D. Chamovitz, G. Sandmann, J. Hirschberg, J. Biol. Chem. 268 (23) (1993) $17348-17353$.

[85] A.J. Simkin, J. Breitenbach, M. Kuntz, G. Sandmann, J. Agric. Food Chem. 48 (2000) 4676-4680.

[86] G. Sandmann, G. Mitchell, J. Agric. Food Chem. 49 (1) (2001) 138-141.

[87] R. León, M. Vila, D. Hernánz, C. Vílchez, Biotechnol. Bioeng. 92 (6) (2005) 695701.

[88] J.K. Campbell, R.B. Rogers, M.A. Lila, J.W. Erdman Jr., J. Agric. Food Chem. 54 (2006) 747-755.

[89] P. Beyer, G. Weiss, H. Kleinig, Eur. J. Biochem. 153 (2) (1985) 341-346.

[90] F. Khachik, C.J. Spangler, J.C. Smith Jr., L.M. Canfield, A. Steck, H. Pfander, Anal. Chem. 69 (1997) 1873-1881.

[91] F. Granado, B. Olmedilla, I. Blanco, E. Rojas-Hidalgo, J. Liq. Chromatogr. 14 (13) (1991) 2457-2475.

[92] S. Rivera, F. Vilaró, R. Canela, Anal. Bioanal. Chem. 400 (5) (2011) 1339-1346.

[93] C.M. Stinco, A.M. Benítez-González, D. Hernanz, I.M. Vicario, A.J. MeléndezMartínez, J. Chromatogr. A 1370 (2014) 162-170.

[94] V.V. De Rosso, A.Z. Mercadante, J. Agric. Food Chem. 55 (13) (2007) 5062 5072.

[95] A.F. De Faria, P.N. Hasegawa, E.A. Chagas, R. Pio, E. Purgatto, A.Z. Mercadante, J. Food Compos. Anal. 22 (3) (2009) 196-203.

[96] V.V. De Rosso, A.Z. Mercadante, J. Agric. Food Chem. 55 (22) (2007) 9135 9141.

[97] R.J. Cogdell, T. Gillbro, P.O. Andersson, R.S.H. Liu, A.E. Asato, Pure Appl. Chem. 66 (5) (1994) 1041-1046.

[98] F.A. Bubb, G.M. Murphy, Clin. Chim. Acta 48 (3) (1973) 329-334.

[99] A.Z. Mercadante, G. Britton, D.B. Rodriguez-Amaya, J. Agric. Food Chem. 46 (1998) 4102-4106.

[100] V.V. Rosso, A.Z. Mercadante, J. Agric. Food Chem. 55 (13) (2007) 5062-5072.

[101] P.D. Fraser, E.M.A. Enfissi, M. Goodfellow, T. Eguchi, P.M. Bramley, Plant J. 49 (2007) 552-564.

[102] P. Granger, B. Maudinas, R. Herber, J. Villoutreix, J. Magn. Reson. 10 (1) (1973) 43-50.

[103] J.M. Clough, G. Pattenden, J. Chem. Soc. Perkin Trans. (1983) 3011-3018
[104] S. Tiziani, S.J. Schwartz, Y. Vodovotz, J. Agric. Food Chem. 54 (16) (2006) 6094-6100.

[105] T. Chisato, M. Takashi, S. Makiko, J. Sep. Sci. 32 (21) (2009) 3659-3663.

[106] D.B. Rodriguez-Amaya, M. Kimura, H.T. Godoy, J. Amaya-Farfan, J. Food Compos. Anal. 21 (6) (2008) 445-463.

[107] G. Britton, F. Khachik, Carotenoids in food, in: G. Britton, S. Liaaen-Jensen, H. Pfander (Eds.), Carotenoids Volume 5: Nutrition and Health, Birkhäuser, Basel, Boston, Berlin, 2009, pp. 45-66.

[108] Y.M. Choo, S.C. Yapa, C.K. Ooi, A.N. Ma, S.H. Goh, A.S.-H. Ong, J. Am. Oil Chem. Soc. Palm Oil Res. 73 (5) (1996) 599-602.

[109] R. Sambanthamurthi, K. Sundram, Y.A. Tan, Prog. Lipid Res. 39 (6) (2000) 507-558.

[110] B.K. Ishida, C. Turner, M.H. Chapman, T.A. McKeon, J. Agric. Food Chem. 52 (2004) 274-279.

[111] C.J. Xu, P.D. Fraser, W.J. Wang, P.M. Bramley, J. Agric. Food Chem. 54 (15) (2006) 5474-5481.

[112] B. Alquezar, M.J. Rodrigo, L. Zacarías, Phytochemistry 69 (10) (2008) 19972007.

[113] M.-J. Rodrigo, J. Exp. Bot. 54 (383) (2003) 727-738.

[114] X. Fu, W. Kong, G. Peng, J. Zhou, M. Azam, C. Xu, et al., J. Exp. Bot. 63 (1) (2012) $341-354$.

[115] E. Biehler, A. Alkerwi, L. Hoffmann, E. Krause, M. Guillaume, M.L. Lair, et al., J. Food Compos. Anal. 25 (1) (2012) 56-65.

[116] A. Basu, V. Imrhan, Eur. J. Clin. Nutr. 61 (3) (2007 Mar) 295-303.

[117] P.F. Jacques, A. Lyass, J.M. Massaro, R.S. Vasan, R.B. D’Agostino Sr., Br. J. Nutr. (2013) 1-7

[118] R.G. Borguini, E.A. Ferraz Da Silva Torres, Food Rev. Int. 25 (4) (2009) 313325.

[119] Q. Shixian, Y. Dai, Y. Kakuda, J. Shi, G. Mittal, D. Yeung, et al., Food Rev. Int. 21 (3) (2005) 295-311.

[120] M.J. Werman, S. Mokady, J. Nutr. Biochem. 13 (10) (2002) 585-591.

[121] J.K. Campbell, N.J. Engelmann, M.A. Lila, J.W. Erdman, Nutr. Res. 27 (12) (2007) 794-801.

[122] A.G. Liu, S.E. Volker, E.H. Jeffery, J.W. Erdman, J. Agric. Food Chem. 57 (16) (2009) 7304-7310 (American Chemical Society).

[123] A. Melendez-Martinez, A.F. Nascimento, Y. Wang, C. Liu, Y. Mao, X.-D. Wang, Hepatobiliary Surg. Nutr. 2 (4) (2013) 198-208.

[124] N.E. Moran, S.K. Clinton, J.W. Erdman, J. Nutr. 143 (12) (2013) 1920-1926.

[125] M.A. Ross, L.K. Crosley, K.M. Brown, S.J. Duthie, A.C. Collins, J.R. Arthur, et al., Eur. J. Clin. Nutr. 49 (11) (1995) 861-865.

[126] I. Paetau, F. Khachik, E.D. Brown, G.R. Beecher, T.R. Kramer, J. Chittams, et al., Int. J. Cancer 68 (6) (1998) 1187-1195.

[127] H. Müller, A. Bub, B. Watzl, G. Rechkemmer, Eur. J. Nutr. 38 (1) (1999) 35-44.

[128] A.J. Edwards, B.T. Vinyard, E.R. Wiley, E.D. Brown, J.K. Collins, P. PerkinsVeazie, et al., J. Nutr. 133 (4) (2003) 1043-1050.

[129] M. Richelle, K. Bortlik, S. Liardet, C. Hager, P. Lambelet, M. Baur, et al., J. Nutr. 132 (3) (2002) 404-408.

[130] O. Aust, W. Stahl, H. Sies, H. Tronnier, U. Heinrich, Int. J. Vitam. Nutr. Res. 75 (1) (2005) 54-60.

[131] M. Porrini, P. Riso, A. Brusamolino, C. Berti, S. Guarnieri, F. Visioli, Br. J. Nutr. 93 (1) (2005) 93-99.

[132] F. Khachik, L. Carvalho, P.S. Bernstein, G.J. Muir, D.-Y. Zhao, N.B. Katz, Exp. Biol. Med. (Maywood) 227 (10) (2002) 845-851.

[133] N.J. Engelmann, J.K. Campbell, R.B. Rogers, S.I. Rupassara, P.J. Garlick, M.A. Lila, et al., J. Agric. Food Chem. 58 (18) (2010) 9979-9987.

[134] N.J. Engelmann, R.B. Rogers, M.A. Lila, W. John, J. Agric. Food Chem. 57 (11) (2009) 4614-4619.

[135] M.M. Mathews-Roth, Oncology 39 (1) (1982) 33-37.

[136] E. Kotake-Nara, M. Kushiro, H. Zhang, T. Sugawara, K. Miyashita, A. Nagao, J. Nutr. 131 (12) (2001) 3303-3306.

[137] T.W.-M. Boileau, Z. Liao, S. Kim, S. Lemeshow, J. Erdman, S.K. Clinton, J. Natl. Cancer Inst. 95 (21) (2003) 1578-1586.

[138] J.K. Campbell, C.K. Stroud, M.T. Nakamura, M.A. Lila, J. Erdman, J. Nutr. 136 (11) (2006) 2813-2819.

[139] E. Nara, H. Hayashi, M. Kotake, K. Miyashita, A. Nagao, Nutr. Cancer 39 (2) (2001) 273-283.

[140] K. Hirsch, A. Atzmon, M. Danilenko, J. Levy, Y. Sharoni, Breast Cancer Res, Treat. 104 (2) (2007) 221-230.

[141] H. Nishino, M. Murakoshi, T. Ii, M. Takemura, M. Kuchide, M. Kanazawa, et al., Cancer Metastasis Rev. 21 (3-4) (2002) 257-264.

[142] A. Shaish, A. Harari, Y. Kamari, E. Soudant, D. Harats, A. Ben-Amotz, Plant Foods Hum. Nutr. 63 (2) (2008) 83-86.

[143] A. Ben-Dor, M. Steiner, L. Gheber, M. Danilenko, N. Dubi, K. Linnewiel, et al., Mol. Cancer Ther. 4 (1) (2005) 177-186.

[144] M.M. Mathews Roth, M.A. Pathak, Photochem. Photobiol. 21 (4) (1975) 261263.

[145] S. Spirt, K. Lutter, W. Stahl, Curr. Nutr. Food Sci. 6 (1) (2010) 36-43.

[146] W. Stahl, H. Sies, Am. J. Clin. Nutr. 96 (2012) 1179-1184.

[147] B. Fuller, D. Smith, A. Howerton, D. Kern, J. Cosmet. Dermatol. 5 (1) (2006) 30-38.

[148] G. Chinetti, J.C. Fruchart, B. Staels, Inflamm. Res. 49 (10) (2000) 497-505.

[149] L. Gijsbers, H.D.L.M. van Eekelen, L.H.J. de Haan, J.M. Swier, N.L. Heijink, S.K. Kloet, et al., J. Agric. Food Chem. 61 (14) (2013) 3419-3427.

[150] C. Dhuique-Mayer, A.L. Fanciullino, C. Dubois, P. Ollitrault, J. Agric. Food Chem. 57 (19) (2009) 9160-9168. 
[151] D. Ruiz, M. Reich, S. Bureau, C.M.G.C. Renard, J.M. Audergon, J. Agric. Food Chem. 56 (13) (2008) 4916-4922.

[152] F. Khachik, G.R. Beecher, W.R. Lusby, J. Agric. Food Chem. 37 (1989) 1465 1473.

[153] P.S. Hamano, A.Z. Mercadante, J. Food Compos. Anal. 14 (2001) 335-343.

[154] R.L. Rouseff, G.D. Sadler, T.J. Putnam, J.E. Davis, J. Agric. Food Chem. 40 (1992) 47-51.
[155] L.H. Tonucci, J.M. Holden, G.R. Beecher, F. Khachik, C.S. Davis, G. Mulokozi, J. Agric. Food Chem. 43 (3) (1995) 579-586.

[156] H. Müller, Z. Lebensm. Unters. Forsch. 204 (2) (1997) 88-94.

[157] N.J. Engelmann, S.K. Clinton, J.W. Erdman, Adv. Nutr. 2 (2011) 51-61. 